\title{
The Efficiency of Operating Microscope Compared with Unaided Visual Examination, Conventional and Digital Intraoral Radiography for Proximal Caries Detection
}

\author{
Ilkay Peker, ${ }^{1}$ Meryem Toraman Alkurt, ${ }^{1}$ Oya Bala, ${ }^{2}$ and Bulent Altunkaynak ${ }^{3}$ \\ ${ }^{1}$ Department of Oral Diagnosis and Radiology, Faculty of Dentistry, Gazi University, 06490 Ankara, Turkey \\ ${ }^{2}$ Department of Operative Dentistry, Faculty of Dentistry, Gazi University, 06490 Ankara, Turkey \\ ${ }^{3}$ Department of Statistics, Faculty of Arts and Sciences, Gazi University, 06490 Ankara, Turkey
}

Correspondence should be addressed to Ilkay Peker, drdtilkay@gmail.com

Received 25 June 2008; Revised 12 September 2008; Accepted 25 November 2008

Recommended by Roland Frankenberger

Objective. The purpose of this study was to evaluate the efficiency of operating microscope compared with unaided visual examination, conventional and digital intraoral radiography for proximal caries detection. Materials and Methods. The study was based on 48 extracted human posterior permanent teeth. The teeth were examined with unaided visual examination, operating microscope, conventional bitewing and digital intraoral radiographs. Then, true caries depth was determined by histological examination. The extent of the carious lesions was assessed by three examiners independently. One way variance of analysis (ANOVA) and Scheffe test were performed for comparison of observers, and the diagnostic accuracies of all systems were assessed from the area under the ROC curve $\left(A_{z}\right)$. Results. Statistically significant difference was found between observers $(P<.01)$. There was a statistically significant difference between operating microscope-film radiography, operating microscopeRVG, unaided visual examination-film radiography, and unaided visual examination-RVG according to pairwise comparison $(P<.05)$. Conclusion. The efficiency of operating microscope was found statistically equal with unaided visual examination and lower than radiographic systems for proximal caries detection.

Copyright (c) 2009 Ilkay Peker et al. This is an open access article distributed under the Creative Commons Attribution License, which permits unrestricted use, distribution, and reproduction in any medium, provided the original work is properly cited.

\section{Introduction}

A variety of test methods are discussed for the diagnosis of proximal tooth surfaces. Adjuncts such as bitewing radiography and fiber-optic transillumination provide an improvement to unaided vision. Unaided visual diagnosis had detected fewer than $50 \%$ of caries lesions on occlusal surfaces and even fewer on proximal surfaces [1].

It is not possible to detect only with unaided visual examination in interproximal caries lesions; radiographs help for proximal caries diagnosis and detection of their lesion depth $[2,3]$. The combination of visual inspection and bitewing radiographic images is accepted as a standard procedure in proximal caries diagnosis [4]. However, proximal radiolucencies on bitewing radiographs are not always indicative of clinical cavitation. The deeper the radiolucency penetrates enamel and dentine, the higher the probability of cavitation [5].

Due to difficulties in proximal caries detection, different methodologies were investigated. Magnification is an accessible, commonly advocated aid to diagnosis [6]. Recently, the new methods of magnifying visual aids such as intraoral camera, magnification loops, and operating microscope are used for caries diagnosis, restorative treatment decisions, root resection, and retrograde canal preparation $[7,8]$. Previous studies $[9,10]$ had investigated the efficiency of operating microscope for occlusal caries diagnosis, but there is insufficient publication $[5,11]$ about usage of this device for proximal caries detection in dental literature.

The purpose of this study was to evaluate the efficiency of operating microscope compared with unaided visual examination, conventional and digital intraoral radiography 
for proximal caries detection by means of receiver operating characteristic (ROC) curve analysis.

\section{Materials and Methods}

The study was based on 48 extracted human posterior permanent teeth, 24 molars and 24 premolars stored in a $5 \%$ buffered formalin solution. No specimens exhibited any restoration on the proximal surfaces. Organic and inorganic debris were removed by an excavator and then the teeth were cleaned by pumice and water slurry. Three mouth models were prepared with the teeth to simulate the clinical condition. The models were fixed in a phantom head which was adjusted to a dental unit during the sessions of unaided visual examination and operating microscope assessment. The proximal surfaces coronal to the cementoenameljunction of the teeth were assessed by two specialists of oral diagnosis and radiology and one specialist of restorative dentistry of at least 10 years of experience independently. To avoid observer fatigue, an interval of at least one week had separated each diagnostic session.

The models were examined under a dental unit light, by using a dental mirror (size 5) and the air water syringe of the dental unit without any magnification for unaided visual examination. The clinicians evaluated the extent of the carious lesions in the proximal surfaces of the teeth according to a 5-point rating scale (Table 1) [5].

Then the teeth were examined using an operating microscope 16x magnification (Moller-Wedel, Dento 300, Wedel, Germany) according to the same scale. The observers assessed the teeth adjusting the height of the operating stool at a 12 o'clock position. The position of operating microscope was not changed to eliminate the position errors during the examinations. Pictures captured on the computer monitor were recorded using a video recorder.

After unaided visual and operating microscope examinations were completed, the teeth were mounted in dental stone models 3 in a row (either 2 premolars and 1 molar or 1 premolar and 2 molars) with proximal surfaces in contact.

Conventional bitewing radiographs of the teeth were obtained using a specially designed holder to provide standardized bitewing projection geometry in the buccolingual direction, tangential to the proximal surfaces. The object to film distance was approximately $0.5 \mathrm{~cm}$ and the source-toimage receptor distance was $32 \mathrm{~cm}$. Size 2 Insight (Eastman Kodak Company, Paris, France) films with an exposure time of 0.16 seconds and CCX intraoral unit (Trophy, Instrumentarium, Tuusula, Finland) with focal spot of size $0.8 \mathrm{~mm}$, operating at $70 \mathrm{kVp}$ and $8 \mathrm{~mA}$, with $2.5 \mathrm{~mm}$ of aluminum-equivalent filtration were used. One centimeter of soft tissue equivalent material was used to simulate scatter radiation and beam attenuation from facial tissues. All film radiographs were developed in automatic film processor (Velopex, Extra-X, Medivance Instruments Ltd., London, UK, and NW107A) with freshly prepared solutions in the same day.

The CCD-based system to be evaluated was the Radiovisiography (RVG, 2000 Model, Trophy Radiologie, Paris,
France). Digital images were obtained with $32 \mathrm{~cm}$ sensor to focal spot distance with an exposure time of 0.08 seconds under the same standardized conditions and were stored using the RVG image management software.

The film radiographs were assessed using a masked light box and a $2 \mathrm{x}$ magnification $\mathrm{X}$-viewer (Luminosa, CSN Industrie, Cinisello Balsamo, Italy) by three clinicians independently in a quiet room with subdued ambient lighting. Images from the digital system were displayed on a 17 -inch monitor in the same ambient lighting. Brightness and contrast features of the software were not changed. The observers indicated their decision separately for each interproximal side of the teeth by masking other side with the use of a black cartoon. They assessed the extent of the carious lesions according to a 5-point rating scale (Table 1) [12].

After all assessments were completed, the teeth were histologically prepared. The proximal surfaces were first colored with a solution of propylene glycol with added basic fucsin $(0.5 \%)$ for 10 seconds and rinsed in tap water. Then, the teeth were hemisectioned perpendicularly to the proximal surfaces from their santral fossas by a diamond disc under watercooling. Two sections were obtained, each section was examined under stereomicroscope (Olympus SZ 60, Tokyo, Japan) with a 10x magnification. Two observers not participating in the study both experienced in histological examination and being blinded to the radiographic appearance of the surfaces evaluated the sections by consensus according to a 5-point confidence scale (Table 1) [12].

Histological validation served as a "gold standard" for all tested methods. One way variance of analysis (ANOVA) and pairwise comparisons (Scheffe test) were performed for comparison of observers. The diagnostic accuracies of the four diagnostic systems were assessed from the area under the ROC curve $\left(A_{z}\right)$. Med-Calc (version 7.3) was used for ROC analysis. The rating scales were dichotomized as "presence" or "absence" of caries during the analysis. Score 0 in both radiographic and histological scales was detected as absence of caries and the others were detected as presence of caries. $A_{z}$ values were calculated for each observer for each diagnostic method. The $A_{z}$ values were analyzed by pairwise comparison of ROC curves. SPSS-version 13.0 for Windows was used for all calculations. The level of statistical significance was $\alpha=0.05$.

\section{Results}

The status of the 96 proximal surfaces of the teeth were assessed. Histological examination of the teeth confirmed that $61(63.54 \%)$ of the proximal surfaces were caries free, whereas $35(36.46 \%)$ of proximal surfaces determined caries lesions of different depths. The numbers of proximal surfaces for each score according to the histological examination are shown in Table 2.

Statistically significant difference was found between three observers at 99\% confidence interval $(P<.01)$ according to ANOVA. Scheffe test from pairwise comparisons was performed to determine which observers were different. No 
TABLE 1: Criteria used for evaluations.

\begin{tabular}{lccc}
\hline Scores & Visual examination \& operating microscope & Radiographic & Histological \\
\hline 0 & No lesion & Sound & Sound \\
1 & Enamel opacity with smooth surface & Radiolucency in enamel & Caries in enamel \\
2 & Enamel opacity with rough surface & Radiolucency in dentino-enamel junction & Caries in dentino-enamel junction \\
3 & Cavitation restricted to the enamel & Radiolucency in the outer half of the dentine & Caries in the outer half of the dentine \\
4 & Cavitation extending into dentine & Radiolucency in the inner half of the dentine & Caries in the inner half of the dentine \\
\hline
\end{tabular}

TABle 2: Histological examination of the teeth.

\begin{tabular}{lcc}
\hline Scores & No. of tooth surfaces & Percent $(\%)$ \\
\hline Score 0 & 61 & 63.54 \\
Score 1 & 3 & 3.12 \\
Score 2 & 12 & 12.5 \\
Score 3 & 2 & 2.09 \\
Score 4 & 18 & 18.75 \\
\hline
\end{tabular}

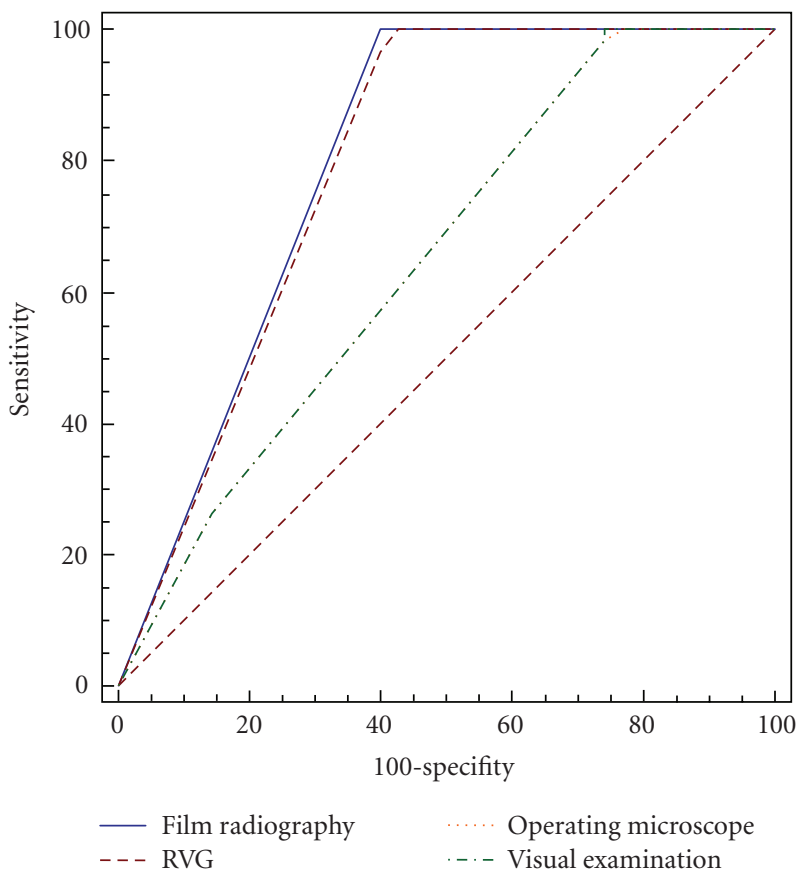

FIGURE 1: ROC curve for 1st observer.

statistically significant difference was found between 1st and 2nd observers $(P<.05)$ and there was statistically significant difference between both 1st and 3rd observers and 2nd and 3rd observers $(P<.01)$ (Table 3$)$.

Two ROC curves are illustrated. The first ROC curve (Figure 1) is illustrated by considering assessments of 1 st observer due to no statistically significant difference between 1st and 2nd observers and the second ROC curve (Figure 2) is illustrated for 3rd observer. Areas under the ROC curve $\left(A_{z}\right)$ and standard errors are shown in Table 4 and analysis of $A_{z}$ values are shown in Table 5.

For both 1st and 3rd observers, no statistically significant difference was found between operating microscope-unaided visual examination and film radiography (Insight)-RVG in

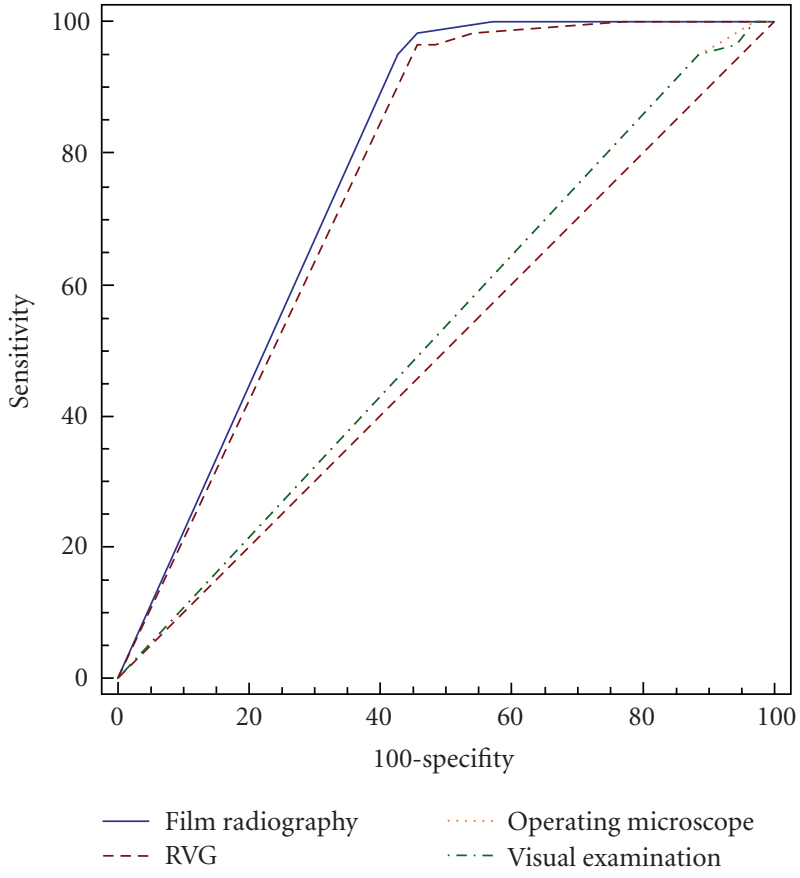

FIgURE 2: ROC curve for 3rd observer.

95\% confidence interval according to pairwise comparison $(P<.05)$. There was a statistically significant difference between operating microscope-film radiography, operating microscope-RVG, unaided visual examination-film radiography, unaided visual examination- RVG in $95 \%$ confidence interval according to pairwise comparison $(P<.05)$ for both 1 st and 3rd observers.

\section{Discussion}

The efficiency of operating microscope was compared with unaided visual examination, film and digital intraoral radiography for proximal caries detection according to ROC analysis in this study.

Recently, many researchers have advocated the use of ROC analysis to assess diagnostic methods for the detection of dental caries [13]. Validity of ROC analysis can be assessed by increasing the number of tooth surfaces, increasing the rating scale, and uniform distribution of caries depths [14]. In this study, the sample was relatively large, 5-point rating scale was used, and the distribution of caries depths was not uniform. Area under the ROC curve $\left(A_{z}\right.$ value) gives useful information to measure accuracy of a diagnostic system [15]. 
TABLE 3: Results of Scheffe test.

\begin{tabular}{|c|c|c|c|c|c|c|}
\hline \multirow{2}{*}{ Observers } & \multirow{2}{*}{ Groups } & \multirow{2}{*}{ Mean difference } & \multirow{2}{*}{ Standard error } & \multirow{2}{*}{$P$ value } & \multicolumn{2}{|c|}{ Asymptotic $95 \%$ confidence interval } \\
\hline & & & & & Lower bound & Upper bound \\
\hline \multirow{2}{*}{1} & 2 & -0.057 & 0.089 & .811 & -0.27 & 0.16 \\
\hline & 3 & $0.531\left(^{*}\right)$ & 0.089 & .000 & 0.31 & 0.75 \\
\hline \multirow{2}{*}{2} & 1 & 0.057 & 0.089 & .811 & -0.16 & 0.27 \\
\hline & 3 & $0.589\left(^{*}\right)$ & 0.089 & .000 & 0.37 & 0.81 \\
\hline \multirow{2}{*}{3} & 1 & $-0.531(*)$ & 0.089 & .000 & -0.75 & -0.31 \\
\hline & 2 & $-0.589\left(^{*}\right)$ & 0.089 & .000 & -0.81 & -0.37 \\
\hline
\end{tabular}

${ }^{*}$ The mean difference is significant at the 0.05 level.

TABLE 4: The $A_{z}$ values and standard errors for 1st and 3rd observers.

\begin{tabular}{|c|c|c|c|c|c|}
\hline & \multirow{2}{*}{ Test result variable (s) } & \multirow{2}{*}{ Area } & \multirow{2}{*}{ Std. error (a) } & \multicolumn{2}{|c|}{ Asymptotic $95 \%$ confidence interval } \\
\hline & & & & Lower bound & Upper bound \\
\hline \multirow{4}{*}{ 1st Observer } & Unaided visual examination & 0.650 & 0.060 & 0.546 & 0.745 \\
\hline & Operating microscope & 0.650 & 0.060 & 0.546 & 0.744 \\
\hline & Film radiography & 0.800 & 0.050 & 0.706 & 0.875 \\
\hline & RVG & 0.793 & 0.051 & 0.698 & 0.869 \\
\hline \multirow{4}{*}{ 3rd Observer } & Unaided visual examination & 0.533 & 0.062 & 0.428 & 0.635 \\
\hline & Operating microscope & 0.533 & 0.062 & 0.429 & 0.636 \\
\hline & Film radiography & 0.773 & 0.052 & 0.677 & 0.853 \\
\hline & RVG & 0.760 & 0.054 & 0.662 & 0.841 \\
\hline
\end{tabular}

The highest $A_{z}$ values belonged to film radiography and RVG for all observers. The $A_{z}$ values of unaided visual examination and operating microscope were equal and lower than the radiographic methods.

A diagnostic tool should be reliable and valid. Interobserver reliability is an important factor for this aim [16]. On the other hand, training and experience of observers may affect intra- and interobserver agreements [17]. Syriopoulos et al. [18] emphasized that diagnosis of the radiologists was significantly closer to actual lesion depth than that of general practitioners. Two of the observers were the specialists of oral diagnosis and radiology, the other observer was a specialist of restorative dentistry of at least 10 years of experience in this study. No statistically significant difference was found between the two specialists of oral diagnosis and radiology for all diagnostic systems $(P<.05)$, but there was a statistically significant difference between the specialist of restorative dentistry and the specialists of oral diagnosis and radiology $(P<.05)$. The $A_{z}$ values were found to be $0.800,0.793$, and 0.650 for film radiography, RVG, and both unaided visual examination and operating microscope, respectively, according to assessments of 1 st observer. The $A_{z}$ values were found to be $0.773,0.760,0.533$ for film radiography, RVG, and both unaided visual examination and operating microscope, respectively, according to assessments of 3rd observer in this study. The $A_{z}$ values of 1st observer were higher than 3 rd observer for all diagnostic methods. This condition may be due to the fact that the specialists of oral diagnosis and radiology were more experienced than other specialists about diagnostic and radiographic methods.
Due to difficulty of proximal caries diagnosis with only visual examination, the combination of visual inspection and bitewing radiographic images is accepted as a standard procedure in proximal caries detection $[5,19]$. Machiulskiene et al. [20] reported that the clinical examination alone detected about $60 \%$ of the total number of proximal cavitated dentin lesions, and bitewing examination detected about $90 \%$ of these lesions. But they emphasized that the clinical examination is a more effective method in noncavitated enamel lesions. In this study, the radiographic methods were better than clinical examinations for proximal caries diagnosis in conformity with previous studies [19, 21].

The positioning of operating microscope is the most common difficultness. The operator should be careful and not change the position as far as possible. It was reported that the ideal operator zones are in the 7 to 12 o'clock positions for right-handed operators, and 5 to 12 o'clock for left ones. The clinicians should conform these suggestions to use operating microscope effectively [22]. The researchers studied at 12 o'clock position and not changed the position of operating microscope during the examinations in this study.

Currently, magnifying visual aids such as magnification eyeglasses, stereo microscope [23], and also digital imaging [24] with magnification are used in proximal caries detection in some studies and they reported that these methods are effective. However, Haak et al. reported that prism loupe or surgical microscope does not improve the ability to diagnose proximal caries [25]. In this study, the efficiency of operating microscope was evaluated by comparing with unaided visual examination, film and digital intraoral radiography 
TABLE 5: Pairwise comparisons of $A_{z}$ values.

\begin{tabular}{|c|c|c|c|c|c|c|}
\hline & \multirow[t]{2}{*}{ Pairwise } & \multirow[t]{2}{*}{ Difference between area } & \multirow[t]{2}{*}{ Std. error (a) } & \multirow[t]{2}{*}{$P$ value } & \multicolumn{2}{|c|}{$\begin{array}{c}\text { Asymptotic } 95 \% \\
\text { confidence interval }\end{array}$} \\
\hline & & & & & Lower bound & Upper bound \\
\hline \multirow{6}{*}{ 1st Observer } & $\begin{array}{l}\text { Operating } \\
\text { microscope-unaided } \\
\text { visual examination }\end{array}$ & 0.000 & 0.051 & .996 & -0.099 & 0.099 \\
\hline & $\begin{array}{l}\text { Operating } \\
\text { microscope-film } \\
\text { radiography }\end{array}$ & 0.150 & 0.072 & .036 & 0.010 & 0.291 \\
\hline & $\begin{array}{l}\text { Operating } \\
\text { microscope-RVG }\end{array}$ & 0.143 & 0.072 & .048 & 0.001 & 0.285 \\
\hline & $\begin{array}{l}\text { Unaided visual } \\
\text { examination-film } \\
\text { radiography }\end{array}$ & 0.150 & 0.072 & .038 & 0.009 & 0.291 \\
\hline & $\begin{array}{l}\text { Unaided visual } \\
\text { examination-RVG }\end{array}$ & 0.143 & 0.073 & .050 & 0.000 & 0.285 \\
\hline & Insight-RVG & 0.007 & 0.054 & .896 & -0.099 & 0.113 \\
\hline \multirow{6}{*}{ 3rd Observer } & $\begin{array}{l}\text { Operating } \\
\text { microscope-unaided } \\
\text { visual examination }\end{array}$ & 0.001 & 0.036 & .984 & -0.070 & 0.071 \\
\hline & $\begin{array}{l}\text { Operating } \\
\text { microscope-film } \\
\text { radiography }\end{array}$ & 0.240 & 0.078 & .002 & 0.087 & 0.393 \\
\hline & $\begin{array}{l}\text { Operating } \\
\text { microscope-RVG }\end{array}$ & 0.226 & 0.078 & .004 & 0.074 & 0.379 \\
\hline & $\begin{array}{l}\text { Unaided visual } \\
\text { examination-film } \\
\text { radiography }\end{array}$ & 0.241 & 0.078 & .002 & 0.088 & 0.394 \\
\hline & $\begin{array}{l}\text { Unaided visual } \\
\text { examination-RVG }\end{array}$ & 0.227 & 0.078 & .003 & 0.075 & 0.380 \\
\hline & $\begin{array}{l}\text { Film } \\
\text { radiography-RVG }\end{array}$ & 0.014 & 0.047 & .772 & -0.078 & 0.106 \\
\hline
\end{tabular}

for proximal caries detection according to ROC analysis. No statistically significant difference was found between operating microscope and unaided visual examination $(P$ $<.05$ ), and there was a statistically significant difference between operating microscope and both two radiographic systems $(P<.05)$.

In conclusion, the efficiency of operating microscope was found statistically equal with unaided visual examination and lower than film and digital intraoral radiography according to ROC analysis. Because the operating microscope is expensive and requires equipment and operator experience, according to the results of this in vitro study it can be said that use of this device would not improve to make an accurate diagnosis of proximal caries lesions. However, the accuracies of diagnostic methods with magnifying visual aids should be investigated and clinical usefulness of these methods in dental practice should be discussed in vitro and in vivo with several studies in which the numbers of samples are larger and rating scales are increased by comparing conventional methods for proximal caries detection.

\section{References}

[1] H. Hintze, A. Wenzel, B. Danielsen, and B. Nyvad, "Reliability of visual examination, fiber-optic transillumination, and bitewing radiography, and reproducibility of direct visual examination following tooth separation for the identification of cavitated carious lesions in contacting approximal surfaces," Caries Research, vol. 32, pp. 204-209, 1998.

[2] S. L. Kogen, R. G. Stephens, J. A. Reid, and A. Donner, "Can radiographic criteria be used to distinguish between cavitated and noncavitated approximal enamel caries?" Dentomaxillofacial Radiology, vol. 16, no. 1, pp. 33-36, 1987. 
[3] J. Bille and A. Thylstrup, "Radiographic diagnosis and clinical tissue changes in relation to treatment of approximal carious lesions," Caries Research, vol. 16, no. 1, pp. 1-6, 1982.

[4] N. B. Pitts, "The use of bitewing radiographs in the management of dental caries: scientific and practical considerations," Dentomaxillofacial Radiology, vol. 25, no. 1, pp. 5-16, 1996.

[5] E. S. Akpata, M. R. Farid, K. al-Saif, and E. A. U. Roberts, "Cavitation at radiolucent areas on proximal surfaces of posterior teeth," Caries Research, vol. 30, no. 5, pp. 313-316, 1996.

[6] A. H. Forgie, C. M. Pine, C. Longbottom, and N. B. Pitts, "The use of magnification in general dental practice in Scotland-a survey report," Journal of Dentistry, vol. 27, no. 7, pp. 497-502, 1999.

[7] A. H. Forgie, C. M. Pine, and N. B. Pitts, "The assessment of an intra-oral video camera as an aid to occlusal caries detection," International Dental Journal, vol. 53, no. 1, pp. 3-6, 2003.

[8] I. Tsesis, Y. Shoshani, N. Givol, R. Yahalom, Z. Fuss, and S. Taicher, "Comparison of quality of life after surgical endodontic treatment using two techniques: a prospective study," Oral Surgery, Oral Medicine, Oral Pathology, Oral Radiology and Endodontology, vol. 99, no. 3, pp. 367-371, 2005.

[9] H. Erten, M. B. Uçtasli, Z. Z. Akarslan, O. Uzun, and E. Baspinar, "The assessment of unaided visual examination, intraoral camera and operating microscope for the detection of occlusal caries lesions," Operative Dentistry, vol. 30, no. 2, pp. 190-194, 2005.

[10] H. Erten, M. B. Uçtasli, Z. Z. Akarslan, O. Uzun, and M. Semiz, "Restorative treatment decision making with unaided visual examination, intraoral camera and operating microscope," Operative Dentistry, vol. 31, no. 1, pp. 55-59, 2006.

[11] E. A. M. Kidd, A. Banerjee, S. Ferrier, C. Longbottom, and Z. Nugent, "Relationships between a clinical-visual scoring system and two histological techniques: a laboratory study on occlusal and approximal carious lesions," Caries Research, vol. 37, no. 2, pp. 125-129, 2003.

[12] H. Hintze, A. Wenzel, and M. Frydenberg, "Accuracy of caries detection with four storage phosphor systems and E-speed radiographs," Dentomaxillofacial Radiology, vol. 31, no. 3, pp. 170-175, 2002.

[13] J. J. ten Bosch and B. Angmar-Månsson, "Characterization and validation of diagnostic methods," Monographs in Oral Science, vol. 17, pp. 174-189, 2000.

[14] E. H. Verdonschot, A. Wenzel, and E. M. Bronkhorst, "Applicability of Receiver Operating Characteristic (ROC) analysis on discrete caries depth ratings," Community Dentistry and Oral Epidemiology, vol. 21, no. 5, pp. 269-272, 1993.

[15] A. R. Henderson, "Assessing test accuracy and its clinical consequences: a primer for receiver operating characteristic curve analysis," Annals of Clinical Biochemistry, vol. 30, no. 6, pp. 521-539, 1993.

[16] H. M. Alwas-Danowska, A. J. M. Plasschaert, S. Suliborski, and E. H. Verdonschot, "Reliability and validity issues of laser fluorescence measurements in occlusal caries diagnosis," Journal of Dentistry, vol. 30, no. 4, pp. 129-134, 2002.

[17] K. Syriopoulos, G. C. H. Sanderink, X. L. Velders, F. C. van Ginkel, and P. F. van der Stelt, "The effects of developer age on diagnostic accuracy: a study using assessment of endodontic file length," Dentomaxillofacial Radiology, vol. 28, no. 5, pp. 311-315, 1999.
[18] K. Syriopoulos, G. C. H. Sanderink, X. L. Velders, and P. F. van der Stelt, "Radiographic detection of approximal caries: a comparison of dental films and digital imaging systems," Dentomaxillofacial Radiology, vol. 29, no. 5, pp. 312-318, 2000.

[19] E. Bloemendal, H. C. W. de Vet, and L. M. Bouter, "The value of bitewing radiographs in epidemiological caries research: a systematic review of the literature," Journal of Dentistry, vol. 32, no. 4, pp. 255-264, 2004.

[20] V. Machiulskiene, B. Nyvad, and V. Baelum, "Comparison of clinical and radiographic caries diagnoses in posterior teeth of 12-year old Lithuanian children," Caries Research, vol. 33, no. 5, pp. 340-348, 1999.

[21] M. S. Hopcraft and M. V. Morgan, "Comparison of radiographic and clinical diagnosis of approximal and occlusal dental caries in a young adult population," Community Dentistry and Oral Epidemiology, vol. 33, no. 3, pp. 212-218, 2005.

[22] Y. Kinomoto, F. Takeshige, M. Hayashi, and S. Ebisu, "Optimal positioning for a dental operating microscope during nonsurgical endodontics," Journal of Endodontics, vol. 30, no. 12, pp. 860-862, 2004.

[23] A. M. Kielbassa, S. Paris, A. Lussi, and H. Meyer-Lueckel, "Evaluation of cavitations in proximal caries lesions at various magnification levels in vitro," Journal of Dentistry, vol. 34, no. 10, pp. 817-822, 2006.

[24] L. Forner Navarro, M. C. Llena Puy, and F. García Godoy, "Diagnostic performance of radiovisiography in combination with a diagnosis assisting program versus conventional radiography and radiovisiography in basic mode and with magnification," Medicina Oral, Patología Oral y Cirugía Bucal, vol. 13, no. 4, pp. E261-E265, 2008.

[25] R. Haak, M. J. Wicht, M. Hellmich, A. Gossmann, and M. J. Noack, "The validity of proximal caries detection using magnifying visual aids," Caries Research, vol. 36, no. 4, pp. 249-255, 2002. 


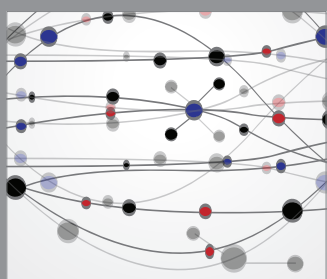

The Scientific World Journal
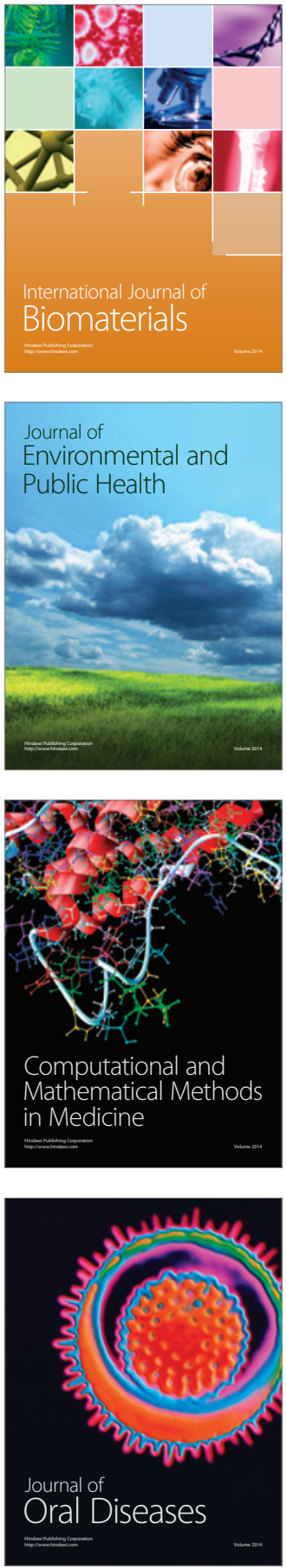
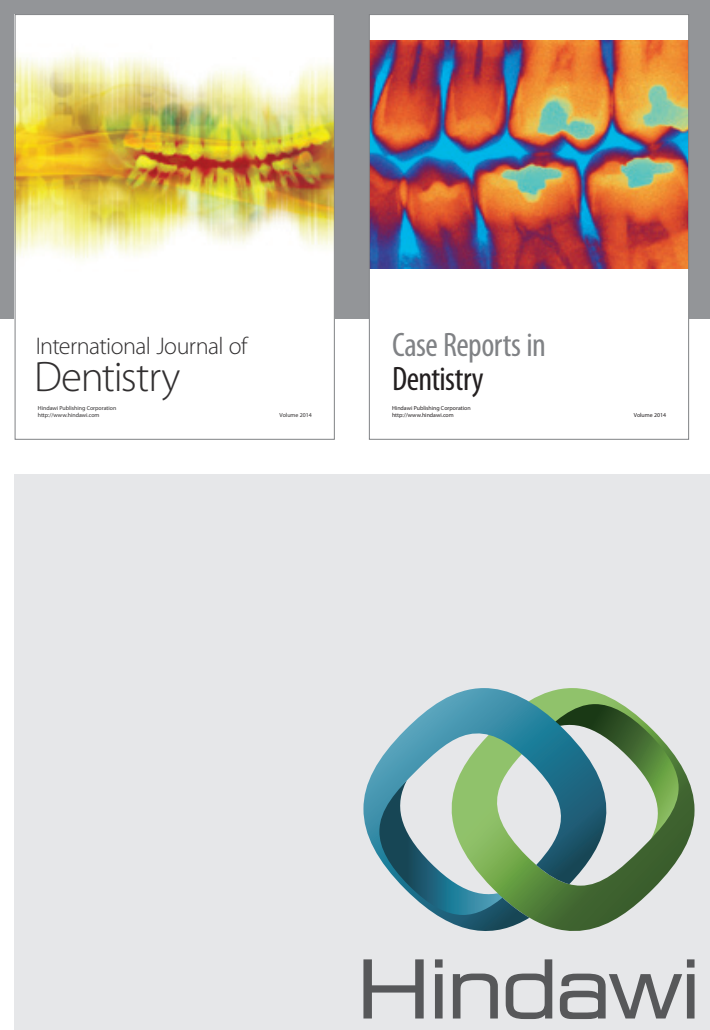

Submit your manuscripts at

http://www.hindawi.com
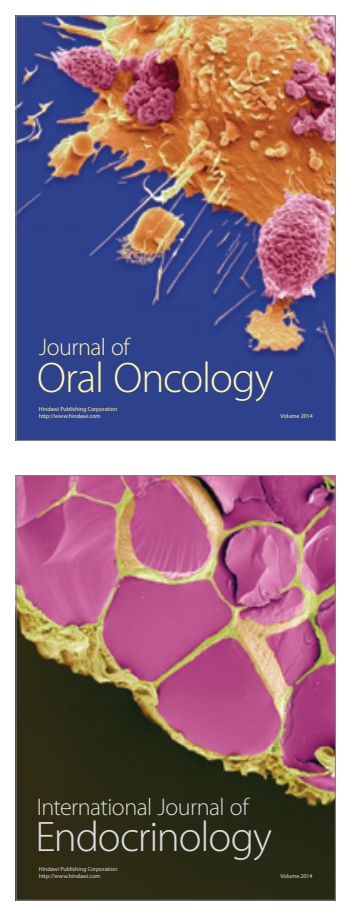
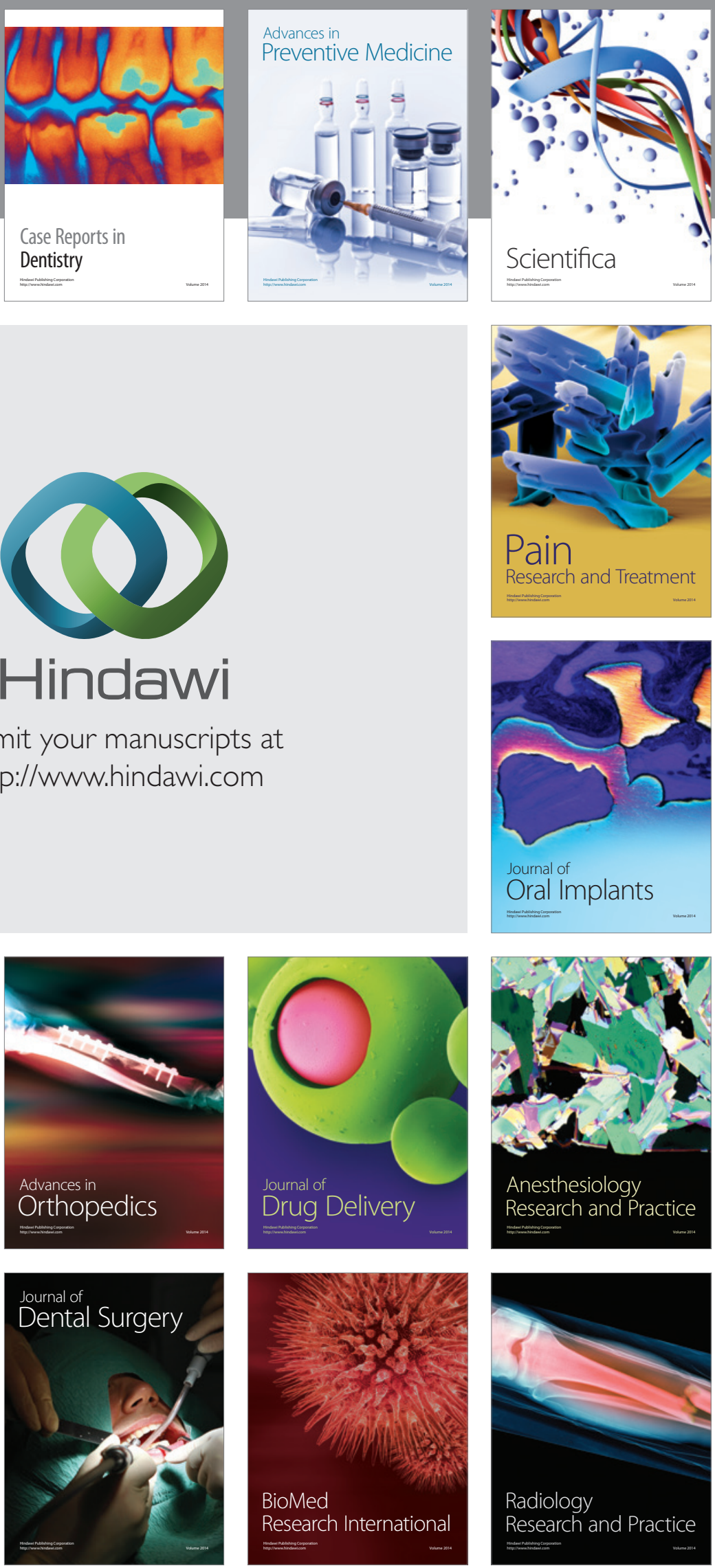